\title{
AVALIAÇÃO DE SISTEMA DE TRATAMENTO DE LATICÍNIO E O EFEITO DO EFLUENTE GERADO NOS ATIBUTOS FISICO-QUÍMICO DE UM ARGISSOLO VERMELHO
}

Jacineumo Falcão Oliveira ${ }^{1}$, Sandra Maria Campos Alves ${ }^{2}$, Rafael Oliveira Batista ${ }^{3}$, Valéria Ingrith Lima ${ }^{4}$, Luiz Di Souza $^{5}$

\section{RESUMO}

Os efluentes gerados em indústrias lácteas possuem elevados teores de matéria orgânica, gorduras, sólidos suspensos e nutrientes, tendo que ser tratado adequadamente. A disposição inadequada destas águas ao solo causam danos como a salinidade, sodicidade, alteração no $\mathrm{pH}$, entre outros. O afluente lácteo foi submetido a um tratamento preliminar/secundário composto por gradeamento e caixa de gordura seguido por lagoa aerada de mistura, sendo o efluente gerado pós-tratamento, aplicado ao solo por sulco de irrigação. Este trabalho objetivou avaliar a eficiência de tratamento do efluente de laticínio e o efeito de seu reuso nos atributos físico-químicos de um Argissolo Vermelho. Foram realizadas análises físico-química, determinando-se RST, RSD, RSS, pH, $\mathrm{Na}^{+}, \mathrm{K}^{+}, \mathrm{Cl}^{-}, \mathrm{CE}$, Dureza, $\mathrm{Ca}^{+2}, \mathrm{Mg}^{+2}$, Nitrito, Nitrato, DBO e DQO para as amostras de efluente e $\mathrm{N}, \mathrm{P}, \mathrm{K}, \mathrm{Ca}^{+2}, \mathrm{Mg}^{+2}, \mathrm{Na}^{+}, \mathrm{CE}$ e $\mathrm{pH}$ das cinco profundidades de solo. Constatou-se eficiência de remoção de $72,14 \%$ para DBO e 56,52\% para DQO. Houve aumento na concentração de $\mathrm{Na}^{+}, \mathrm{P}, \mathrm{Cl}^{-}$no efluente tratado, este fato foi possivelmente ocasionado devido ao acúmulo de lodo na lagoa aerada. A maior concentração de $\mathrm{Na}^{+}$no solo ocorreu na camada de 0-10 cm de profundidade, com valor de $1373,6 \mathrm{cmol}_{\mathrm{c}} \mathrm{dm}^{-3}$, reduzindo-se sequencialmente nas camadas seguintes. A maior concentração de magnésio $\left(\mathrm{Mg}^{2+}\right)$ foi de 4,00 $\mathrm{cmol}_{c} \mathrm{dm}^{-3}$ na camada de 40-50 $\mathrm{cm}$ de profundidade.

Palavras-chave: reuso, contaminação de solos, capim tifton

\section{ABSTRACT \\ EVALUATION OF TREATMENT AND EFFECT SYSTEM DAIRY WASTE GENERATED IN PHYSICAL AND CHEMICAL ATIBUTOS AN ULTISOL}

The effluents generated in dairy industries have high levels of organic matter, fats, nutrients and suspended solids, having to be treated properly. The improper disposal of these waters causes damage to the soil and salinity, sodicity, change in $\mathrm{pH}$, among others. The milk was subjected to a tributary / secondary preliminary treatment consists of railing and grease trap followed by mixing aerated pond, and the effluent generated after treatment applied to the soil furrow irrigation This study aimed to evaluate the efficiency of dairy effluent treatment and reuse its effect in the physical-chemical properties of an argisoil red furrow irrigated. Analyzed for physico-chemical, determining TS, $\mathrm{SD}, \mathrm{SS}, \mathrm{pH}, \mathrm{Na}^{+}, \mathrm{K}^{+}, \mathrm{Cl}^{-}, \mathrm{CE}$, hardness, $\mathrm{Ca}^{+2}$, $\mathrm{Mg}^{+2}$, nitriti, nitrate, $\mathrm{COD}$ and $\mathrm{BOD}$ for the samples of effluent. Was evaluated the characteristics of $\mathrm{N}, \mathrm{P}, \mathrm{K}, \mathrm{Ca}^{+2}, \mathrm{Mg}^{+2}, \mathrm{Na}^{+}$, $\mathrm{E}$ Cand $\mathrm{pH}$ from five depths of. It found removal efficiency of $72.14 \%$ for BOD and $56.52 \%$ for COD. There was an increase in the concentration of $\mathrm{Na}^{+}, \mathrm{P}, \mathrm{Cl}^{-}$in the treated effluent, this fact possibly caused due to accumulation of logo in aerated lagoon. The highest concentration of $\left(\mathrm{Na}^{+}\right)$in the soil occurred at the $0-10 \mathrm{~cm}$ depth, with a value of $1373.6 \mathrm{cmolcdm}^{-3}$, decreasing sequentially in the following layers. The higher concentration of magnesium $\left(\mathrm{Mg}^{+2}\right)$ was $4.00 \mathrm{cmolcdm}^{-3}$ in the layer of 40-50 cm depth, this occurred because of their high mobility in soil.

Keywords: reuse, soil contamination, grass tifton

Recebido para publicação em 30/07/2013. Aprovado em 03/12/2013.

1 - Estudante de Mestrado, UFV. jacineumo@hotmail.com

2 - Bolsista PDJ/CNPq, Universidade Federal Rural do Semiárido. ettualy@yahoo.com.au

3 - Professor Adjunto I, Universidade Federal Rural do Semiárido. rafaelbatista@ufersa.edu.br

4 - Graduada em Engenharia Agrícola, Universidade Federal Rural do Semiárido. valeria_ialima@hotmail.com

5 - Professor Adjunto I, Universidade Estadual do Rio Grande do Norte. luizuern@bol.com.br

58 REVENG

58-66p. ENGENHARIA NA AGRICULTURA, VIÇOSA - MG, V.22 N.1, JANEIRO / FEVEREIRO 2014 


\section{INTRODUÇÃO}

A indústria de laticínios representa uma atividade de grande importância na economia brasileira e mundial. O Brasil já é o sexto maior produtor mundial de leite (EMBRAPA, 2010) e possui condições para se tornar um dos maiores exportadores de produtos lácteos devido às suas vantagens tais como disponibilidade de água e terra e custo de produção competitivo.

Nos países desenvolvidos, o reuso de efluentes nas indústrias já é uma realidade, entretanto, o Brasil ainda enfrenta dificuldades nessa área. Enquanto nos Estados Unidos cerca de $60 \%$ das indústrias possuem sistemas para reuso de efluentes, no Brasil este montante equivale apenas 1\% (FURTADO, 2005). Este cenário se deve principalmente à falta de alternativas de tratamento que gerem efluentes com a qualidade requerida para reuso.

$\mathrm{O}$ volume de água consumido e de efluente gerado em indústrias de laticínios pode variar muito dependendo do tipo de processo utilizado, dos produtos produzidos, da qualidade da água requerida e das práticas de gestão aplicadas (VOURCH et al., 2008). Daufin et al. (2001) relatam que a relação entre o volume de leite processado e o volume de efluente gerado, chamada de coeficiente volumétrico de efluente líquido, pode oscilar entre 0,2 e 111 litros de efluente por litro de leite processado.

Os efluentes líquidos gerados nos processos de produção de laticínios possuem elevados teores de matéria orgânica, gorduras, sólidos suspensos e nutrientes, e são considerados a principal fonte de poluição dessas indústrias. Diversos problemas durante o tratamento convencional desses efluentes, que normalmente inclui tratamento primário para remoção de sólidos suspensos e gorduras e tratamento secundário biológico, têm sido relatados. Esses problemas estão relacionados à elevada produção de escuma, à baixa sedimentabilidade do lodo, à baixa resistência a choques de carga, às dificuldades na remoção de nutrientes (nitrogênio e fósforo) e aos problemas na degradação de gorduras, óleos e outros tipos específicos de poluentes, como corantes (CAMMAROTA; FREIRE, 2006; MACHADO et al., 2002).

Segundo Valdez-Aguilar e Reed (2010) águas de irrigação com baixa condutividade elétrica e predomínio de $\mathrm{HCO}_{3}$ podem acarretar aumento do $\mathrm{pH}$ do solo, consequentemente diminuindo a disponibilidade dos nutrientes do solo, podendo acentuar a deficiência dos nutrientes, principalmente de micronutrientes

Os problemas no solo associados ao uso de águas residuárias estão relacionados à salinidade, sodicidade, ao excesso de nutrientes, aos bicarbonatos e a variação do $\mathrm{pH}$. A presença de sais no solo reduz a disponibilidade de água para as plantas e pode tornar os solos inadequados ao cultivo (AYERS; WESTCOT, 1999).

De acordo com Varallo et al. (2010), o reuso de água na agricultura, se bem manejado, traz um aumento na produção e evita grande utilização de compostos químicos sintéticos, evitando a poluição do ambiente e trazendo economias nos custos, contribuindo também para o abastecimento do lençol freático. Mas, se mal manejadas, podem contaminar o solo com metais pesados, salinidade e microrganismos patógenos à saúde humana e animal, trazendo danos à saúde pública.

Diante desta problemática, o presente trabalho teve o objetivo de avaliar a eficiência do sistema de tratamento preliminar/secundário composto por gradeamento e caixa de gordura seguida de lagoa aerada de mistura, bem como os efeitos do efluente de laticínio aplicado em um argissolo vermelho.

\section{MATERIAL E MÉTODOS}

A pesquisa foi desenvolvida em uma empresa de laticínio em Mossoró/RN com localização geográfica $5^{\circ} 11$ ' $47^{\prime \prime}$ S e $37^{\circ} 18^{\prime} 36^{\prime \prime} \mathrm{W}$, sendo o clima classificado como tipo BSwh', isto é, clima seco e muito quente, apresentando temperatura média anual de $27,4{ }^{\circ} \mathrm{C}$ (CARMO FILHO; OLIVEIRA, 1995). Os principais produtos gerados na empresa são o queijo e a manteiga. O queijo pode ser considerado como um concentrado de proteína e gordura do leite, obtido pela precipitação ou coagulação da caseína que, arrastando a gordura, vai formar o coágulo (MINAS AMBIENTE, 2002).

A indústria de laticínios em estudo, de pequeno porte, tem como característica o grande consumo de água, utilizados tanto nas operações de processamento, na limpeza dos tanques, dos caminhões e maquinários, gerando em média 20.000 litros de água residuária diariamente. Após tratamento preliminar/secundário composto por gradeamento e caixa de gordura seguido de uma 
lagoa aerada de mistura, uma parcela com área de $225 \mathrm{~m}^{2}(15 \times 15 \mathrm{~m})$ foi utilizada na produção de capim elefante (Pennisetum purpureum, Schum). Determinou-se a dose com base nas recomendações para a cultura enfatizando o nitrogênio por esta ser o nutriente de maior demanda para as gramíneas.

No cálculo da dosagem da água residuária foi empregado o método do EPA (1981) onde o nitrogênio é usado como nutriente limitante para que não ocorra contaminação das águas subterrâneas com nitrato em níveis acima dos aceitáveis $\left(10 \mathrm{mg} \mathrm{L}^{-1}\right)$.

$L_{w}=\frac{C_{p} \cdot(P R-E T)+U \cdot 10}{(1-f) \cdot C_{n}-C_{p}}$

em que,

$\mathrm{L}_{\mathrm{w}}=$ lâmina de aplicação anual, $\mathrm{cm}^{\mathrm{ano}} \mathrm{o}^{-1}$;

$\mathrm{C}_{\mathrm{p}}^{\mathrm{w}}=$ concentração de nitrogênio na água de percolação, $\mathrm{mg} \mathrm{L}^{-1}$;

$\mathrm{PR}=$ taxa de precipitação local, $\mathrm{cm}$ ano ${ }^{-1}$;

$\mathrm{ET}=$ taxa de evapotranspiração da cultura local, $\mathrm{cm} \mathrm{ano}^{-1}$;

$\mathrm{U}=$ absorção de nitrogênio pela cultura, $\mathrm{kg}$ ha ${ }^{-1} \mathrm{ano}^{-1}$;

$\mathrm{C}_{\mathrm{n}}=$ concentração de nitrogênio na água residuária, $\mathrm{mg} \mathrm{L}^{-1} ; \mathrm{e}$

$\mathrm{F}=$ fração de nitrogênio aplicada que é removido por desnitrificação e volatilização.

A dosagem obtida com o método do EPA (1981) foi de $521 \mathrm{~mm}^{2} \mathrm{ano}^{-1}$, e as irrigações foram realizadas diariamente, durante um período de cinco anos.

Observa-se na Figura 1, o esquema do processamento do leite na indústria em estudo, os tratamentos aplicados no efluente bruto gerado, bem como aplicação do efluente de laticínio tratado na área cultivada com capim elefante.

A caracterização físico-química da água residuária do laticínio foi realizada por meio da coleta de três amostras compostas no período de novembro a dezembro de 2013. Cada amostra composta foi obtida de três amostras simples coletadas às 8:00 h, 11:00 h e 14:00 h, em dois pontos do sistema de tratamento (P1 - efluente coletado a montante do gradeamento/caixa de gordura e P2 efluente coletado a jusante da lagoa aerada). A lagoa apresenta dois aeradores com densidade de potência de $30 \mathrm{~W} / \mathrm{m}^{3}$ e potência de 4 cv. Após a coleta as amostras foram preservadas em caixas isotérmicas com gelo a temperatura de $4{ }^{\circ} \mathrm{C}$ até sua entrada nos laboratórios. As amostras compostas dos efluentes foram encaminhadas para o Laboratório de Diagnóstico Físico-Químico da Universidade Estadual do Rio Grande do Norte (UERN). As análises físico-químicas compreenderam: Demanda Bioquímica de Oxigênio $\left(\mathrm{DBO}_{5}^{20}\right)$ obtida pelo método iodométrico (processo Winkler); Demanda Química de Oxigênio (DQO), obtida pelo método oxidimétrico com refluxo; sólidos totais (ST), obtidos pelo método gravimétrico; sólidos suspensos (SS), empregando-se o método gravimétrico com a utilização de membranas de fibra de vidro $(0,45$ $\mu \mathrm{m}$ de diâmetro de poro); sólidos dissolvidos (SD), obtidos pela diferença entre as concentrações de ST e SS; potássio $\left(\mathrm{K}^{+}\right)$e sódio $\left(\mathrm{Na}^{+}\right)$, empregandose fotometria de emissão de chama; potencial hidrogeniônico $(\mathrm{pH})$, medido com peagâmetro portátil; cálcio $\left(\mathrm{Ca}^{2+}\right)$ e magnésio $\left(\mathrm{Mg}^{2+}\right)$, obtidos

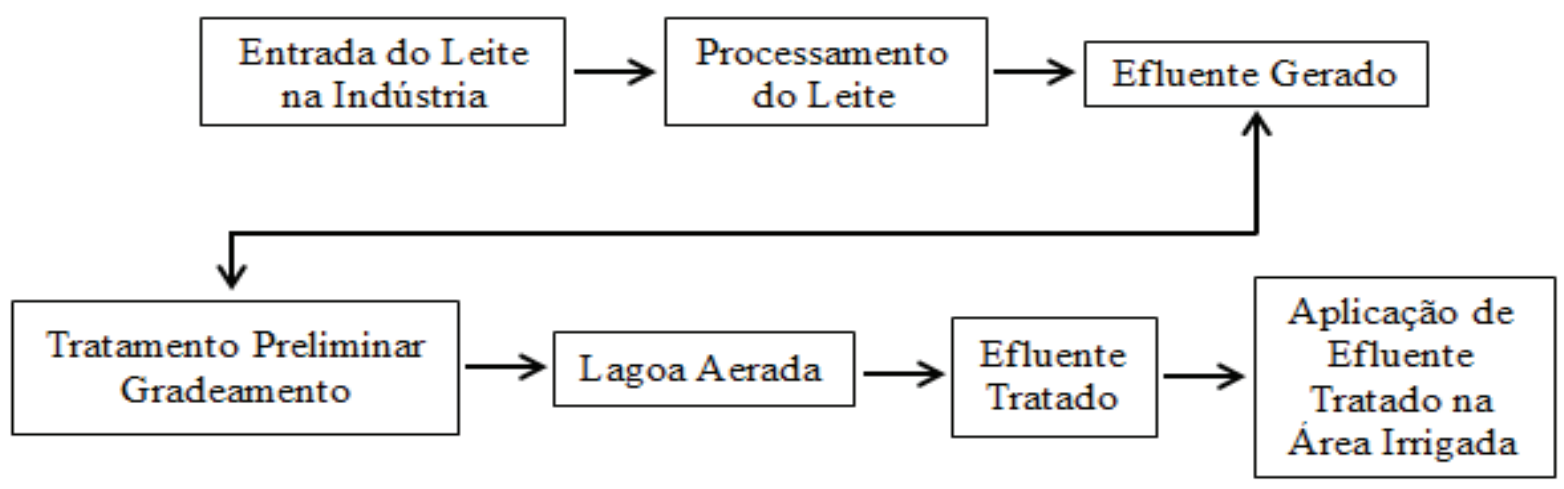

Figura 1. Esquema do processamento do leite e sistema de tratamento e aplicação do efluente de laticínios. 
pelo método titulométrico; condutividade elétrica através de condutivímetro digital in loco; cloreto $\left(\mathrm{Cl}^{-1}\right)$, nitrato $\left(\mathrm{NO}_{3}^{-}\right)$e nitrito $\left(\mathrm{NO}_{2}^{-}\right)$empregando-se espectrometria UV-visível, e dureza, determinada por titulação. Ressalta-se, também, que as análises físico-químicas seguiram as recomendações do Standard Methods for the Examination of Water and Wastewater (Rice et al., 2012). As remoções das características químicas da água residuária de laticínios foram obtidas empregando-se a equação 2 .

$$
\mathrm{R}=100\left(\frac{\mathrm{C}_{\mathrm{J}}}{\mathrm{C}_{\mathrm{M}}}\right)
$$

em que,

ER - eficiência de remoção de características químicas da água residuária, \%;

$\mathrm{C}_{\mathrm{J}}$ - concentração das características químicas na água residuária coletada à jusante da lagoa aerada, $\mathrm{mg} \mathrm{L}^{-1}$ ou mmolc L $\mathrm{L}^{-1 ; \mathrm{e}}$

$\mathrm{C}_{\mathrm{M}}$ - concentração das características químicas na água residuária coletada à montante do gradeamento, $\mathrm{mg} \mathrm{L}^{-1}$ ou mmolc $\mathrm{L}^{-1}$

O solo foi caracterizado como sendo um Argissolo Vermelho, no qual foram coletadas amostras de solo na área cultivada com capim elefante nas seguintes profundidades: $0-10,10-20,20-30,30-$ 40 e $40-50 \mathrm{~cm}$ para determinação dos teores de $\mathrm{N}$, $\mathrm{P}, \mathrm{Na}^{+}$disponíveis. Foi determinado o $\mathrm{pH}$ do solo nas devidas profundidades, seus resultados foram interpretados de acordo com Alvarez et al. (1999).

As amostras de solo foram secadas ao ar e peneiradas em malha de $2 \mathrm{~mm}$. A determinação do nitrogênio total do solo foi realizada através da digestão com ácido sulfúrico, e determinada pelo método Kjeldhal. O fósforo disponível foi determinado pelo método colorimétrico. $\mathrm{O}$ sódio $\left(\mathrm{Na}^{+}\right)$foi obtido por fotometria de emissão de chama, utilizando extrator Mehlich, conforme a técnicas descritas pela Embrapa (1997).

As características químicas do solo da área cultivada e da área nativa foram determinadas a partir de análises realizadas no Laboratório de Fertilidade do Solo e Nutrição de Plantas, Departamento de Ciências Ambientais e Tecnológicas, Setor de Solos da Universidade Federal Rural do Semi-Árido (UFERSA).

Os critérios a serem utilizados para a interpretação dos resultados de análises de solos foram definidos de acordo com a Comissão de Fertilidade do Solo do Estado de Minas Gerais (RIBEIRO et al.,1999). Embora a avaliação seja geral, sem levar em consideração o tipo de solo, o clima, a cultura e o manejo, a utilização destes critérios permite diferenciar glebas ou talhões com diferentes probabilidades de resposta à adição de nutrientes, ou seja, pertencentes a diferentes classes de fertilidade do solo.

Realizou-se amostragem de solo em área nativa da caatinga, próximo a indústria em estudo, para servir de base nas avaliações da área irrigada com efluente de laticínio, sendo os dados químicos da área nativa mostrados no Quadro 1.

Quadro 1. Determinação dos dados químicos iniciais de uma área nativa da caatinga próxima a área de lançamento de efluente de laticínio.

\begin{tabular}{ccccc}
\hline Profundidade (m) & $\begin{array}{c}\mathrm{N} \\
\mathrm{g} \mathrm{kg}^{-1}\end{array}$ & $\begin{array}{c}\mathrm{P} \\
\mathrm{mg} \mathrm{dm}^{3}\end{array}$ & $\mathrm{pH}$ & $\begin{array}{c}\mathrm{CE} \\
\mathrm{dS} \mathrm{m}^{-1}\end{array}$ \\
\hline $0-0,10$ & 1,82 & 17,8 & 5,24 & 0,18 \\
$0,10-0,20$ & 1,4 & 15 & 4,24 & 0,35 \\
$0,20-0,30$ & 1,26 & 14,9 & 5,1 & 0,07 \\
$0,30-0,40$ & 1,12 & 15 & 4,9 & 0,15 \\
$0,40-0,50$ & 0,7 & 15 & 5,09 & 0,12 \\
\hline
\end{tabular}




\section{RESULTADOS E DISCUSSÃO}

A eficiência do sistema de tratamento preliminar em interação com a lagoa aerada é expressa através dos parâmetros analisados do Quadro 2, onde se observa valores de afluente e efluente. $\mathrm{O}$ sistema de tratamento proporcionou remoções de Sólido Total (ST), Sólido Dissolvido (SD) e Sólido Suspenso (SS) de 51,54, 48,80 e 65,45\%, respectivamente. De maneira semelhante, Campos et al., (2004), estudando a avaliação da eficiência do reator UASB tratando efluente de laticínio sob diferentes cargas orgânicas, constataram remoção de sólidos voláteis totais devido a materiais de fácil biodegradação, tais como proteínas, açúcares, lipídios, etc, presentes no efluente.

Foi constatado aumento no Potencial Hidrogeniônico (pH) entre efluente $(7,74)$ e afluente $(4,66)$ após o tratamento quando comparados afluente e efluente, provavelmente devido a acumulação de sais no sistema que possibilitou uma ligeira alcalização da água residuária (Quadro 2). De acordo com a resolução Brasil (2005), que dispõem entre outros sobre as condições e padrões de lançamento de efluentes tratados em corpos hídricos, o valor de $\mathrm{pH}$ determinado no efluente tratado deve encontrar-se dentro da faixa de 5 a 9 .

Observou-se aumento na concentração de sódio $\left(\mathrm{Na}^{+}\right)$, variando entre afluente $\left(166 \mathrm{mg} \mathrm{L}^{-1}\right)$ e efluente $\left(548,50 \mathrm{mg} \mathrm{L}^{-1}\right)$. Os níveis de Potássio $\left(\mathrm{K}^{+}\right)$e Cloreto $\left(\mathrm{Cl}^{-}\right)$obtiveram um acréscimo de concentração significativo no efluente tratado, este fato pode estar relacionado ao tempo de funcionamento do sistema de tratamento sem qualquer limpeza prévia durante seus cinco anos de funcionamento (Quadro 2).

Segundo Brasil (2005), os valores de $\mathrm{Na}^{+}$estão acima dos níveis de limites máximos exigidos para potabilidade $\left(8,7 \mathrm{mmolc}^{-1}\right)$. Da mesma forma, tal característica não impede a recomendação dessa água para irrigação de cultivos agrícolas por seu valor médio ser inferior a 3,0 mmolc $\mathrm{L}^{-1}$ (AYERS; WESTCOT, 1999). Costa (2012) constatou remoções de $\mathrm{K}^{+}$e $\mathrm{Cl}^{-}$na faixa de $42,20 \%$ e $29,90 \%$, respectivamente, em esgotos tratados por decantodigestor. A resolução CONAMA 430 de 2011 determina que os limites máximos de cloretos $\left(\mathrm{Cl}^{-}\right)$ em ambientes lênticos deve ser de $0,020 \mathrm{mg} \mathrm{L}^{-1}$, logo, os valores encontrados estão bem acima dos limites determinados pela legislação vigente.
O sistema de tratamento proporcionou uma eficiência de remoção média de $22,22 \%$ para a CE do efluente. $O$ valor médio da CE $\left(1292 \mathrm{dS} \mathrm{m}^{-1}\right)$ foi superior ao obtido por Batista et al. (2006) em estudo com esgoto doméstico terciário. A dureza é um dos parâmetros utilizados para determinar a qualidade da água, indicando a concentração de cátions em solução (VON SPERLING, 2007). Houve uma redução na dureza do efluente em torno de 37,50\%.

As concentrações de cálcio $\left(\mathrm{Ca}^{2+}\right)$ e magnésio $\left(\mathrm{Mg}^{2+}\right)$ foram reduzidas 33,33 e $50,00 \%$ respectivamente (Quadro 2). Batista et al. (2006) observaram concentrações médias de $\mathrm{Ca}^{2+}{\mathrm{e} \mathrm{Mg}^{2+}}^{2+}$

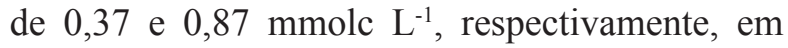
esgoto doméstico terciários.

Os níveis de nitrato variaram entre 7,07 e 0,77mg $\mathrm{L}^{-1}$ entre afluente e efluente respectivamente, obtendo-se remoção média de $88,24 \%$.

As concentrações encontradas de nitrato no nosso trabalho, estão inferiores ao limite de potabilidade de $10 \mathrm{mg} \mathrm{L}^{-1}$ da resolução CONAMA $357 / 2005$, atendendo assim a nossa legislação vigente. Tais valores médios foram inferiores aos obtidos por Reinaldo et al. (2012). Os efeitos dos sistemas de tratamentos do efluente de laticínio proporcionaram remoção de 33,33\% nos níveis de nitrito no efluente tratado (Quadro 2).

O sistema de tratamento promoveu redução na concentração da DQO em torno de 56,52\%, com variação de $1632,20\left(\mathrm{mg} \mathrm{L}^{-1}\right)$ no afluente e $709,70(\mathrm{mg}$ $\left.\mathrm{L}^{-1}\right)$ no efluente. Houve redução de $79,14 \%$ na concentração da $\mathrm{DBO}_{5}$, com variação de 912,80 (mg $\left.\mathrm{L}^{-1}\right)$ no afluente e 190,40 (mg L-1) no efluente após tratamento (Tabela 2). De acordo com a Resolução CONAMA 430/2011, o efluente de laticínio tratado esta acima do limite de $120\left(\mathrm{mg} \mathrm{L}^{-1}\right)$ de carga de DBO para lançamento em corpos hídricos. Machado et al.(2002) afirmam que a relação entre DBO/DQO para os efluentes lácteos se encontram entre 0,50 e 0,70 , constatando que valores fora dessa faixa são indicadores de efluente de natureza incomum.

Janczukowicz et al. (2008) caracterizaram os efluentes gerados em diversos setores de uma mesma indústria de laticínios (recebimento de leite, processamento de leite, produção de creme, manteiga e queijo e a junção de todos os efluentes). Os autores observaram elevadas variações nas concentrações de DQO, DBO e sólidos suspensos, que oscilaram entre 2.543 e $14.639,798$ e 3.470 e 654 e $5.067\left(\mathrm{mg} \mathrm{L}^{-1}\right)$, respectivamente. 
Quadro 2.Caracterização físico-química do afluente e efluente de indústria de laticínio no município de Mossoró-RN.

\begin{tabular}{|c|c|c|c|}
\hline $\begin{array}{c}\text { Parâmetros } \\
\text { Físico-Químicos }\end{array}$ & Afluente & Efluente & Remoção \\
\hline $\mathrm{ST}\left(\mathrm{mg} \mathrm{L}^{-1}\right)$ & 499,8 & 242,2 & 51,54 \\
\hline $\mathrm{SD}\left(\mathrm{mg} \mathrm{L}^{-1}\right)$ & 417,6 & 213,8 & 48,8 \\
\hline $\mathrm{SS}\left(\mathrm{mg} \mathrm{L}^{-1}\right)$ & 82,2 & 28,4 & 65,45 \\
\hline $\mathrm{pH}\left(25^{\circ} \mathrm{C}\right)$ & 4,66 & 7,74 & - \\
\hline Sódio $\left(\mathrm{mg} \mathrm{L}^{-1}\right)$ & 166 & 548,5 & - \\
\hline Potássio $\left(\mathrm{mg} \mathrm{L}^{-1}\right)$ & 35 & 138,5 & - \\
\hline Cloreto (mg L ${ }^{-1}$ ) & 196 & 1064 & - \\
\hline $\mathrm{CE}\left(\mathrm{dS} \mathrm{m} \mathrm{m}^{-1}\right)$ & 1453,5 & 1130,5 & 22,22 \\
\hline Dureza & 320 & 200 & 37,5 \\
\hline Cálcio $\left(\mathrm{mg} \mathrm{L}^{-1}\right)$ & 96 & 64 & 33,33 \\
\hline $\begin{array}{l}\text { Magnésio Total } \\
\left(\mathrm{mg} \mathrm{L}^{-1}\right)\end{array}$ & 19,2 & 9,6 & 50 \\
\hline Nitrato $\left(\mathrm{mg} \mathrm{L}^{-1}\right)$ & 7,02 & 0,77 & 89,03 \\
\hline Nitrito $\left(\mathrm{mg} \mathrm{L}^{-1}\right)$ & 0,04 & 0,06 & - \\
\hline DQO $\left(\mathrm{mg} \mathrm{L}^{-1}\right)$ & 1632,2 & 709,7 & 56,52 \\
\hline $\mathrm{DBO}\left(\mathrm{mg} \mathrm{L}^{-1}\right)$ & 912,8 & 190,4 & 79,14 \\
\hline
\end{tabular}

Observa-se na Figura 2A que o maior teor de nitrogênio $(\mathrm{N})$ foi de $2,17 \mathrm{~g} \mathrm{~kg}^{-1}$ encontrado na camada de $0-10 \mathrm{~cm}$, e reduzindo de acordo com o aumento da profundidade do solo. Constatouse melhor ajuste dos dados através da equação exponencial para o $\mathrm{N}$, evidenciando uma resposta positiva ao modelo testado com $\mathrm{R}^{2}$ de 0,887 .

As observações acima podem ser explicadas devido ao fato de que, a maior parte do nitrogênio presente em águas residuárias encontra-se na forma orgânica, que pode ser mineralizada após serem dispostos no solo (SANTOS et al., 2006).

Os valores de fósforo $(\mathrm{P})$ diminuíram ao longo do perfil do solo de acordo com o aumento de profundidade. A maior concentração de $\mathrm{P}$ foi obtida na profundidade $0-10 \mathrm{~cm}$, com valor de $520,70 \mathrm{mg}$ $\mathrm{dm}^{-3}$ (Figura 2B). A curva exponencial com $\mathrm{R}^{2}=$ 0,897 foi que melhor se ajustou aos dados expostos. Scherer et al. (2010), estudando os atributos químicos do solo influenciados por sucessivas aplicações de dejetos suínos em áreas agrícolas de Santa Catarina, verificaram que o uso prolongado de dejetos de suínos proporcionou o acúmulo de fósforo e potássio nas camadas superficiais do solo.
Os valores de $\mathrm{pH}$ aumentaram de acordo com a profundidade do solo, observando-se o maior valor na camada de 40-50cm (Figura 2C). A média do $\mathrm{pH}$ foi 7,81, que, de acordo com Alvarez et al. (1999), quanto a classificação química, o solo apresenta alcalinidade elevada por estar acima de 7,80. Essa condição preconiza inibição de alguns elementos químicos no solo pelas raízes das plantas, causando deficiência e retardando o crescimento e desenvolvimento do ciclo vegetativo.

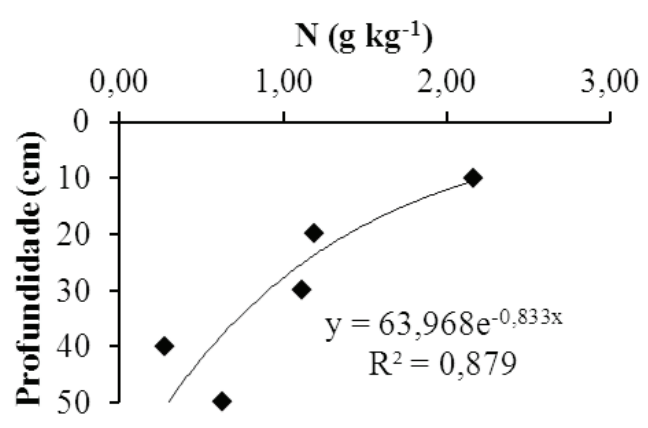

(A)

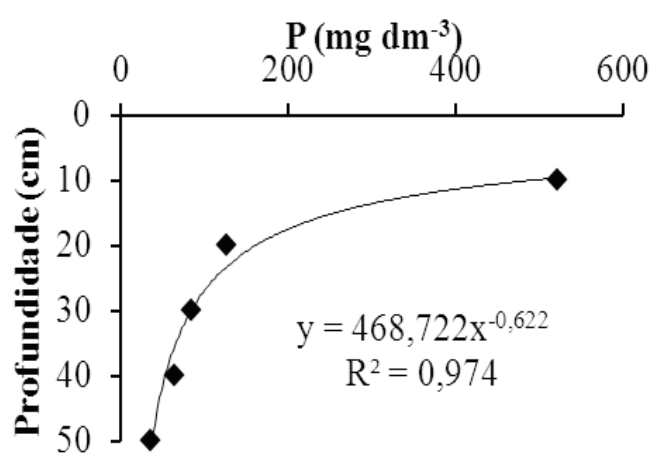

(B)

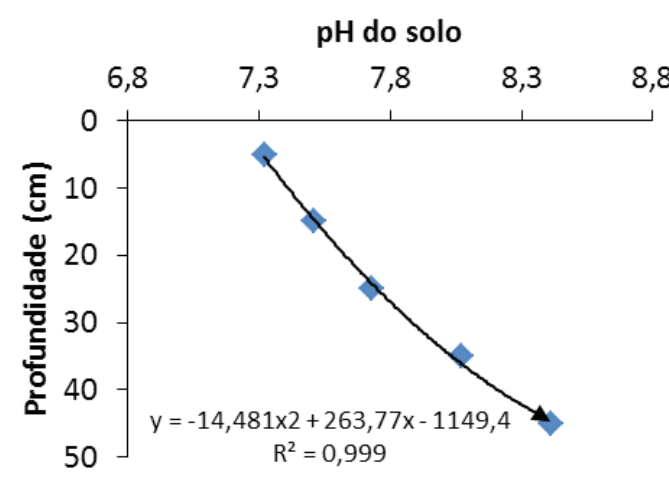

(C)

Figura 2. Valores de nitrogênio $(\mathrm{N})$, fósforo $(\mathrm{P})$ e pH no perfil do Argissolo Vermelho submetido à irrigado com efluente de indústria de laticínios em diferentes profundidades. 
Fonseca et al. (2007) afirmaram que as principais alterações descritas para os solos fertirrigados com águas residuárias se resumem aos efeitos sobre carbono e nitrogênio totais, atividade microbiana e N-mineral, cálcio e magnésio trocáveis, salinidade, sodicidade e dispersão de argilas.

A presença de sódio $\left(\mathrm{Na}^{+}\right)$na água de irrigação sob determinadas condições pode provocar decréscimo na permeabilidade do solo; entretanto, por se tratar de um cátion muito móvel pode, em regiões de altos índices pluviométricos, se movimentar em direção às águas subterrâneas, contaminando-as (SILVA et al., 2010). Nesse sentido, foi constatado que a maior concentração de sódio $\left(\mathrm{Na}^{+}\right)$ocorreu na camada de 0-10 cm de profundidade, apresentando valor de 1373,6 cmol $_{\mathrm{c}} \mathrm{dm}^{-3}$, reduzindo-se, sequencialmente, nas camadas em estudo do solo (Figura 3).

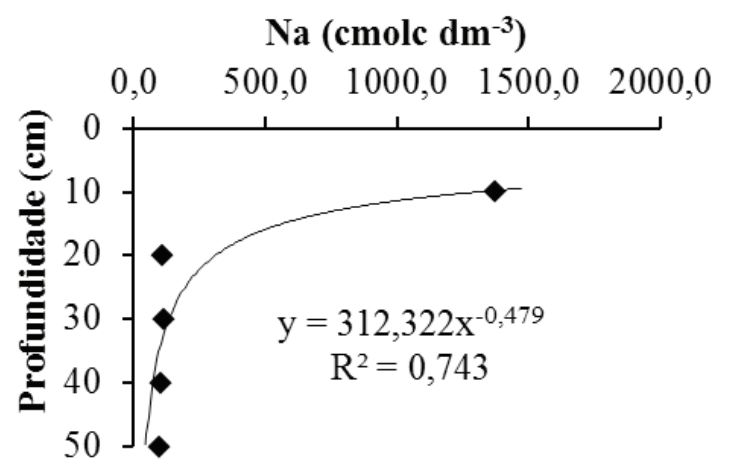

Figura 3. Valores de sódio $\left(\mathrm{Na}^{+}\right)$no perfil do Argissolo Vermelho submetido à irrigado com efluente de indústria de laticínios em diferentes profundidades.

\section{CONCLUSÃO}

- O sistema de tratamento proporcionou remoção dos níveis de nitrato, $\mathrm{DBO}_{5}$, DQO, RST, RSS e RSD. Entretanto, observou-se aumento nas concentrações de sódio, potássio e cloreto no efluente tratado, decorrente da manutenção inadequada do sistema de tratamento, recomendando-se realizar limpezas periódicas para retirada excessiva do lodo no fundo da lagoa aerada e inserir um tratamento primário para complementar o sistema como um todo.
- Constatou-se que após cinco anos de irrigação via sulco com efluente lácteo, o solo apresentou valores elevados de nitrogênio e fósforo. O sódio apresentou elevada concentração, provavelmente devido a constante aplicação do efluente de alta salinidade, sendo necessário um manejo mais adequado, que conduza à lixiviação dos sais, viabilizando seu uso na irrigação e evitando possível efeito tóxico às plantas e degradação física do solo.

\section{REFERÊNCIAS BIBLIOGRÁFICAS}

ALVAREZ V., V.H.; NOVAIS, R.F.; BARROS, N.F.; CANTARUTTI, R.B.; LOPES, A.S. Interpretação dos resultados das análises de solos. In: RIBEIRO, A.C.; GUIMARÃES, P.T.G.; ALVAREZ V., V.H. (Ed.). Recomendação para o uso de corretivos e fertilizantes em Minas Gerais: 5. Aproximação. Viçosa: Comissão de Fertilidade do Solo do Estado de Minas Gerais, 1999. p.25-32.

AYERS, R.S.; WESTCOT, D.W. A qualidade da água na agricultura. Campina Grande: UFPB, 1999. 153p.

BATISTA, R.O.; SOARES, A.A.; SANTOS, D.B. Riscos da fertirrigação com esgoto sanitário e as relações entre os íons $\mathrm{Ca}^{2+}$ e $\mathrm{Mg}^{2+}$ e a salinidade total. Revista Ceres, Viçosa, v.53, n.307, p.394-398, 2006.

BRASIL (2005). Resolução $\mathbf{n}^{\mathbf{0}}$ 357, de 17 de março de 2005. Dispõe sobre a classificação dos corpos de água e diretrizes ambientais para o seu enquadramento, bem como estabelece as condições e padrões de lançamento de efluentes. 2005. Disponível em: $<$ http://www. siam.mg.gov. $\mathrm{br} /$ sla/download.pdf? idNorma $=2747>$. Acessoem: 31 maio. 2012.

CAMMAROTA, M.C.; FREIRE, D.M.G.A review on hydrolytic enzymes in the treatment of wastewater with high oil and grease content. Bioresource Technology, New York, v.97, n.17, p.2195-2210, 2006.

CAMPOS, C.M.M.; LUIZ, F.A.R.; BOTELO, C.G.; DAMASCENO, L.H.S. Avaliação da 
eficiência do reator UASB tratando efluente de laticínio sob diferentes cargas orgânicas. Revista Ciência e Agrotecnologia, Lavras, v.28, n.6, p.1376-1384, 2004.

CARMO FILHO, F.; OLIVEIRA, O.F. Mossoró: Um município do semiárido nordestino, caracterização climática e aspecto florístico. Mossoró: ESAM, 1995. 62p. Coleção Mossoroense, Série B.

SCHERER, E.E.; NESI, C.N.; MASSOTI, Z. Atributos químicos do solo influenciados por sucessivas aplicações de dejetos suínos em áreas agrícolas de Santa Catarina. Revista Brasileira Ciência do Solo,Viçosa, v.34, n.4, p.1375-1383, 2010.

COSTA, F.G.B. Uso de água residuária de origem doméstica no cultivo do girassol no assentamento milagres, Apodi-RN, 2012, 92f. Dissertação (Mestrado em Irrigação e Drenagem), Universidade Federal Rural do Semi-Árido, Mossoró, 2012.

DAUFIN, G.; ESCUDIER, J.P.; CARRERE, H.; BEROT, S.; FILLAUDEAU, L.; DECLOUX, M. Recent and emerging applications of membrane processes in the food and dairy industry. Food and Bioproducts Processing, Orlando, v.79, n.2, p.89102, 2001.

EMPRESA BRASILEIRA DE PESQUISA AGROPECUARIA - EMBRAPA. Agência de informação Embrapa: Agronegócio do leite. Disponível em: < http://www.agencia.cnptia. embrapa.br/Agencia8/AG01/Abertura.html>. Acesso em 07 nov. 2010.

EMPRESA BRASILEIRA DE PESQUISA AGROPECUÁRIA-EMBRAPA. Manual de métodos de análise de solo. 2. ed. Rio de Janeiro, Centro Nacional de Pesquisa de Solos, 1997. 212p.

ENVIRONMENTAL PROTECTION AGENCY. Process design manual - land treatment of municipal wastewater. Washington, D.C.: Department of the interior, 1981. 625p.
FEIGIN， A.; RAVINA， I.; SHALHEVET，J. Irrigation with treated sewage effluent. Advanced Series in Agricultural Science, 1991. 216p.

FONSECA, A.F.; HERPIM, U.; PAULA, A.M.; VICTÓRIA, R. L.; MELFI, A. J. Agricultural use of treated sewage effluents: Agronomic and environmental implications and perspectives for Brazil. Scientia Agrícola, v.64, n.2, p.194-209, 2007.

FURTADO, M.R. Reuso de Água - Tarifas em alta incentivam os primeiros projetos na indústria. Disponível em: < http://www.quimica. com.br/revista/qd444/reuso1.html $>$. Acesso em 09 nov. 2010.

Google Earth 7.0.2. Disponível em: http://earth. google.com/. Acesso em: 5 Mai. 2013.

HUSSAR, G.J.; BASTOS, M.C. Tratamento de efluente de psicultura com macrófitas aquáticas flutuantes. Engenharia Ambiental, Espírito Santo do Pinhal, v.5, n.3, p.274-285, 2008.

JANCZUKOWICZ, W.; ZIELIŃSKI, M.; DĘBOWSKI, M. Biodegradability evaluation of dairy effluents originated in selected sections of dairy production. Bioresource Technology, New York, v.99, n.10, p.4199-4205, 2008.

MACHADO, R.M.G.; FREIRE, V.H.; SILVA, P.C.; FIGUERÊDO, D.V.; FERREIRA, P.E. Controle ambiental nas pequenas e médias indústrias de laticínios. 1 ed. Belo Horizonte: Segrac, 2002, 223p.

MATOS, A.T. Disposição de águas residuárias no solo. Viçosa, MG: AEAGRI, 2007. 140p. (Caderno didático n.38).

MINAS AMBIENTE. Controle Ambiental nas Pequenas e Médias Indústrias de Laticínios, Projeto Minas Ambiente. 2002, cap.1, p.19-26; cap.2, p.27-47; cap.4, p.81-96; cap.5 p.97-136.

REINALDO, G.P.B.; BATISTA, R.O.; SILVA, P.C.M.; LEMOS FILHO, L.C.A.; FERREIRA NETO, M. SANTOS, D.B. Desempenho de sistema decanto-digestor com filtro biológico seguido por 
alagado construído e reator solar no tratamento de esgoto doméstico. Revista Ambiente \& Agua, Taubaté, v.7, n.2, p.62-74, 2012.

RIBEIRO, A.C.; GUIMARÃES, P.T.G.; ALVAREZ, V.H. (Ed.). Recomendações para o uso de corretivos e fertilizantes em Minas Gerais: $5^{\text {a }}$ aproximação. Viçosa -MG: UFV, p. 25-32, 1999.

SANTOS, S.S; SOARES A.A.; MATOS, A.T.; MANTOVANI, E.C.; BATISTA, R.O. Efeitos da aplicação localizada de esgoto sanitário tratado nas características químicas do solo. Engenharia na Agricultura, Viçosa, v.14 n.1, p.32-38. 2006.

SCHACHTSCHABEL, P. Das pflanzenverfügbare magnesium des bodens und seine Bestimmung. Journal of Plant Nutrition Soil Science. Araucaína, v.67, issue.1, p. 9-23, 1954.

SILVA, D.F.; MATOS, A.T.; PEREIRA, O.G.;
CECON, P.R.; MOREIRA, D.A. Disponibilidade de sódio em solo com capim tifton e aplicação de percolado de resíduo sólido. Revista Brasileira de Engenharia Agrícola e Ambiental. Campina Grande, v.14, n.10, p.1094-1100, 2010.

VALDEZ-AGUILAR, L.A, REED, D.W. Growth and nutrition of young bean plants underhigh alkalinity as affected by mixtures of ammonium, potassium, and sodium. Journal of Plantnutrition, n.33, p.1472-1488, 2010.

VARALLO, A.C.T.; CARVALHO, L.; SANTORO, B.L.; SOUZA, C.F. Alterações nos atributos de um Latossolo Vermelho Amarelo irrigado com água de reuso. Revista Brasileira de Engenharia Agrícola e Ambiental, v.14, p.372-377, 2010.

VOURCH, M.; BALANNEC, B.; CHAUFER, B.; DORANGE, G. Treatment of dairyindustry wastewater by reverse osmosis for water reuse. Desalination, Orlando, v.219, p.190-202, 2008. 